\title{
Community Development Program Melalui Pembuatan Website MI Darul Hikmah Al-Hasani Joyosuko Metro
}

\author{
Angga Dwi Mulyanto, Usman Pagalay, Ach Nasichuddin, Hisyam Fahmi, Intan Nisfulaila, Dian Maharani, \\ Dedy Zulkharnain \\ Program Studi Matematika, UIN Maulana Malik Ibrahim Malang \\ angga.dwi.m@mat.uin-malang.ac.id,usman@mat.uin-malang.ac.id,achmadnasichuddin@uin-malang.ac.id, \\ hisyam.fahmi@uin-malang.ac.id,i.nisfulaila@uin-malang.ac.id,dian.maharani@mat.uin-malang.ac.id, \\ dedyzulkharnain37@gmail.com
}

\begin{tabular}{l} 
Info Artikel \\
\hline Riwayat Artikel: \\
Diterima: Agustus 2021 \\
Direvisi: Agustus 2021 \\
Diterbitkan: September 2021
\end{tabular}

\section{Keywords:}

School Website

Development Program

Participatory Action Research

\begin{abstract}
The school website is one of the most important things for a new school. It is the medium for conveying information to the public. Madrasah Ibtidaiyah (elementary school) Darul Hikmah Al-Hasani is a new school that has been being fostered by UIN Maulana Malik Ibrahim Malang which has not had a website yet. For this reason, the community development program team has provided and assisted the development of a website for the school to promote the school. by using the PAR (Participatory Action Research) method, a website has been produced with the address dhimalang.sch.id. The team have prepared a template for each pages and the school just needs to fill it in according to the sections that have been prepared.
\end{abstract}

\section{Korespondensi:}

Intan Nisfulaila,

UIN Maulana Malik Ibrahim Malang,

Jl. Gajayana No. 50 Malang, Jawa Timur, Indonesia 65144

i.nisfulaila@uin-malang.ac.id

\section{PENDAHULUAN}

Website sekolah merupakan hal yang penting saat ini yang perlu dimiliki oleh suatu sekolah. Dengan adanya website tersebut, informasi terkait sekolah bisa dipublish kepada masyarakat. Sebagai sekolah baru, MI Darul Hikmah Al-Hasani belum memiliki website sekolah. Untuk itu fokus pengabdian kami adalah pembuatan website sekolah. MI Darul Hikmah Al-Hasani, yang terletak di daerah Joyosuko Metro merupakan sekolah binaan dari UIN Maulana Malik Ibrahim Malang. Sekolah ini berjarak kurang lebih $1.5 \mathrm{~km}$ dari UIN Maulana Malik Ibrahim Malang.

Suasana MI Darul Hikmah Al-Hasani saat ini masih sangat asri karena dikelilingi alam. Jarak MI Darul Hikmah Al-Hasani dengan pemukiman penduduk saat ini adalah sekitar $450 \mathrm{~m}$, di mana saat perjalanan menuju sekolah tersebut melintasi sungai Metro yang sedang dibangun sebuah kawasan ekowisata yang juga menjadi tempat kegiatan pengabdian UIN Maulana Malik Ibrahim Malang. Beberapa meter setelah melewati sungai Metro kondisi jalan masih berupa tanah dan bebatuan. Melihat kondisi disekitar lokasi yang masih sangat asri tersebut, sangat cocok bila MI Darul Hikmah Al-Hasani ini mengembangkan konsep edukasi berbasis konservasi. 
Kondisi MI Darul Hikmah Al-Hasani saat ini sedang proses pembangunan.Belum ada gapura dan pembangunannya saat ini sedang berjalan. Karena sekolah yang baru dibuka, maka siswanya saat ini hanya ada 5 siswa. MI Darul Hikmah Al-Hasani saat ini masih banyak memerlukan pengembangan tidak hanya dari segi fisik, namun juga dari segi pelaksanaan pendidikan. Hasil wawancara kami dengan salah satu pengurus diketahui bahwa sekolah ini memerlukan pembuatan website sekolah sebagai sarana publikasi sekolah. Diagram alur digunakan untuk menggambarkan berbagai permasalahan yang sedang dihadapi oleh MI Darul Hikmah Al-Hasani.

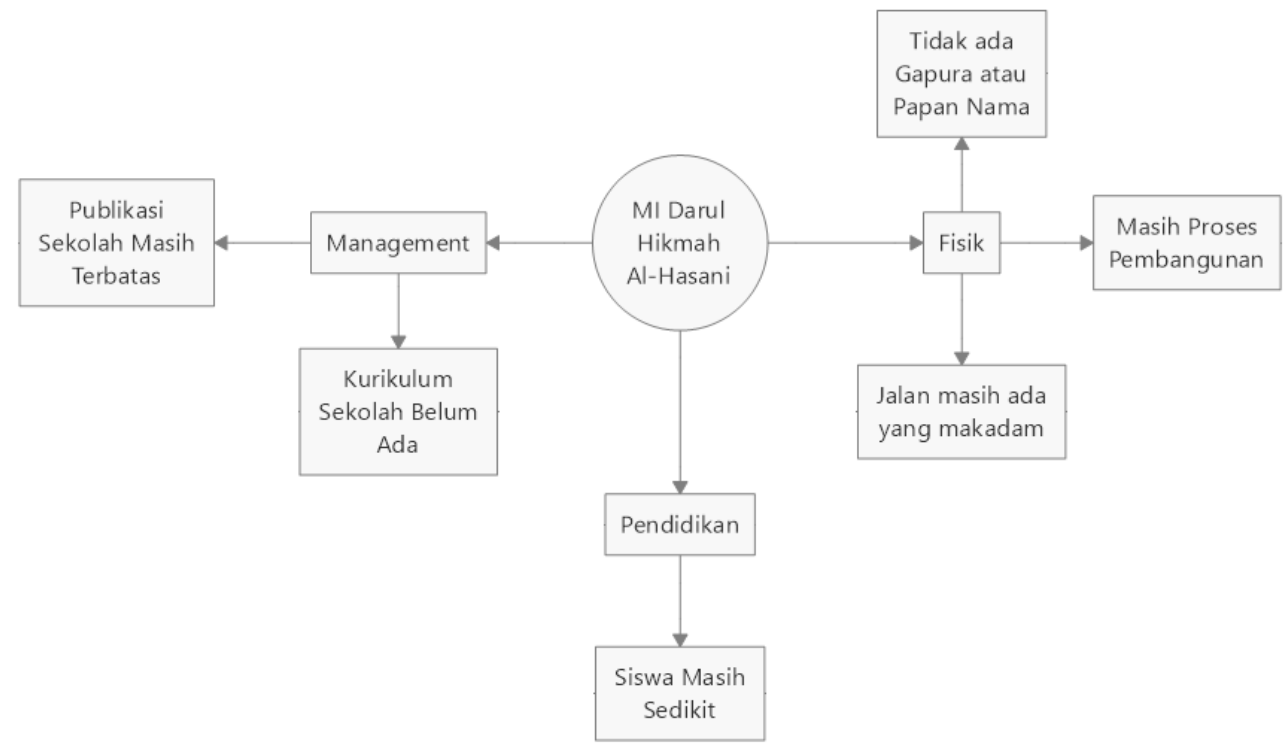

Gambar 1. Diagram Alur MI Darul Hikmah Al Hasani

Berdasarkan Gambar 1, permasalahan dikelompokkan menjadi 3 hal, yaitu manajemen, fisik, dan pendidikan. Dari segi fisik, belum ada gapura atau papan nama, bangunan juga sedang dibangun, serta beberapa meter jalan masih makadam. Dari segi pendidikan, banyanya siswa masih sangat sedikit. Dari segi manajemen, publikasi sekolah masih terbatas dan kurikulum sekolah masih belum ada.

Adanya website sekolah diharapkan sekolah dapat memulai aktifitas publikasinya (termasuk juga info pendaftaran dan lain sebagainya). Sehingga output dari pengabdian ini adalah website sekolah. Untuk Outcome dari pengabdian ini diharapkan berupa artikel pengabdian. Benefit dari pengabdian ini adalah sekolah dapat memiliki website sebagai media informasi. Dampak dari pengabdian ini cukup besar karena website merupakan salah satu hal utama yang harus dimiliki oleh sekolah saat ini.

\section{METODE PENELITIAN}

Kegiatan pengabdian ini menggunakan metode PAR (Participatory Action Research) dengan langkah-langkah sebagai berikut:

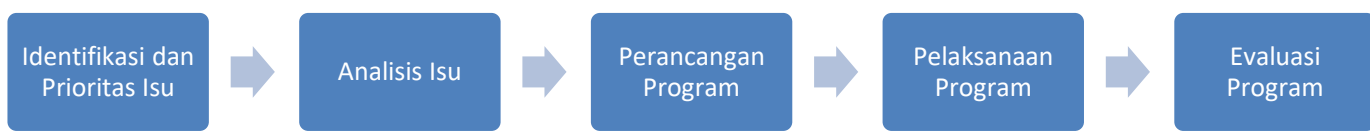

Gambar 2. Metode Pelaksanaan PAR 


\section{HASIL DAN PEMBAHASAN}

Kegiatan pengabdian ini menghasilkan output berupa website sekolah dengan alamat website https://dhimalang.sch.id/. Proses awal sampai terbentuknya alamat website tersebut beserta isinya dapat dilihat secara garis besar pada Tabel 1. Berikut beberapa tampilan dari website yang sudah terbentuk.

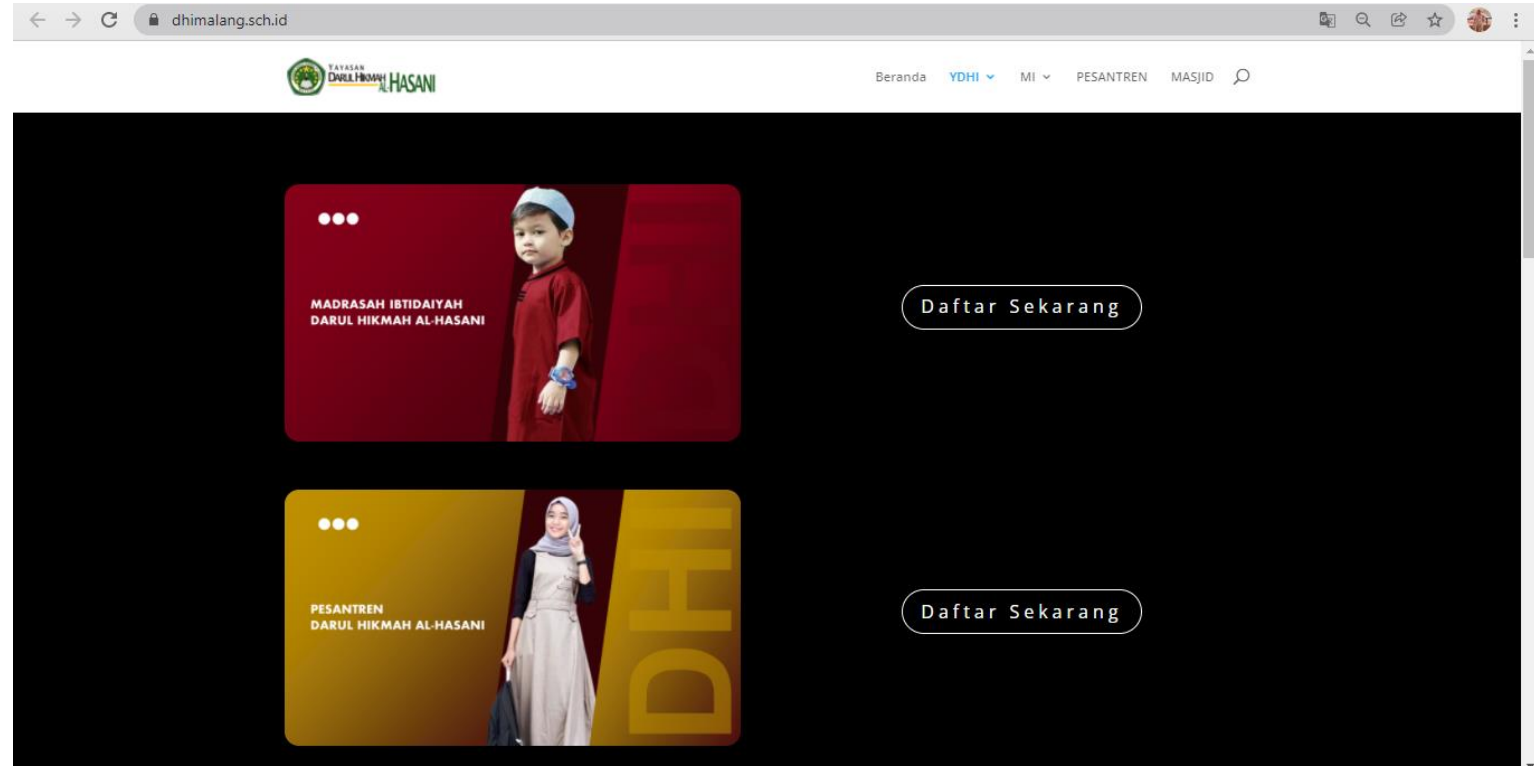

Gambar 3. Tampilan Awal Website

Tampilan awal diharapkan dapat menarik perhatian para pencari informasi dalam menemukan gambaran besar isi website yang terbagi menjadi dua bagian, yaitu bagian khusus madrasah dan bagian khusus pesantren.

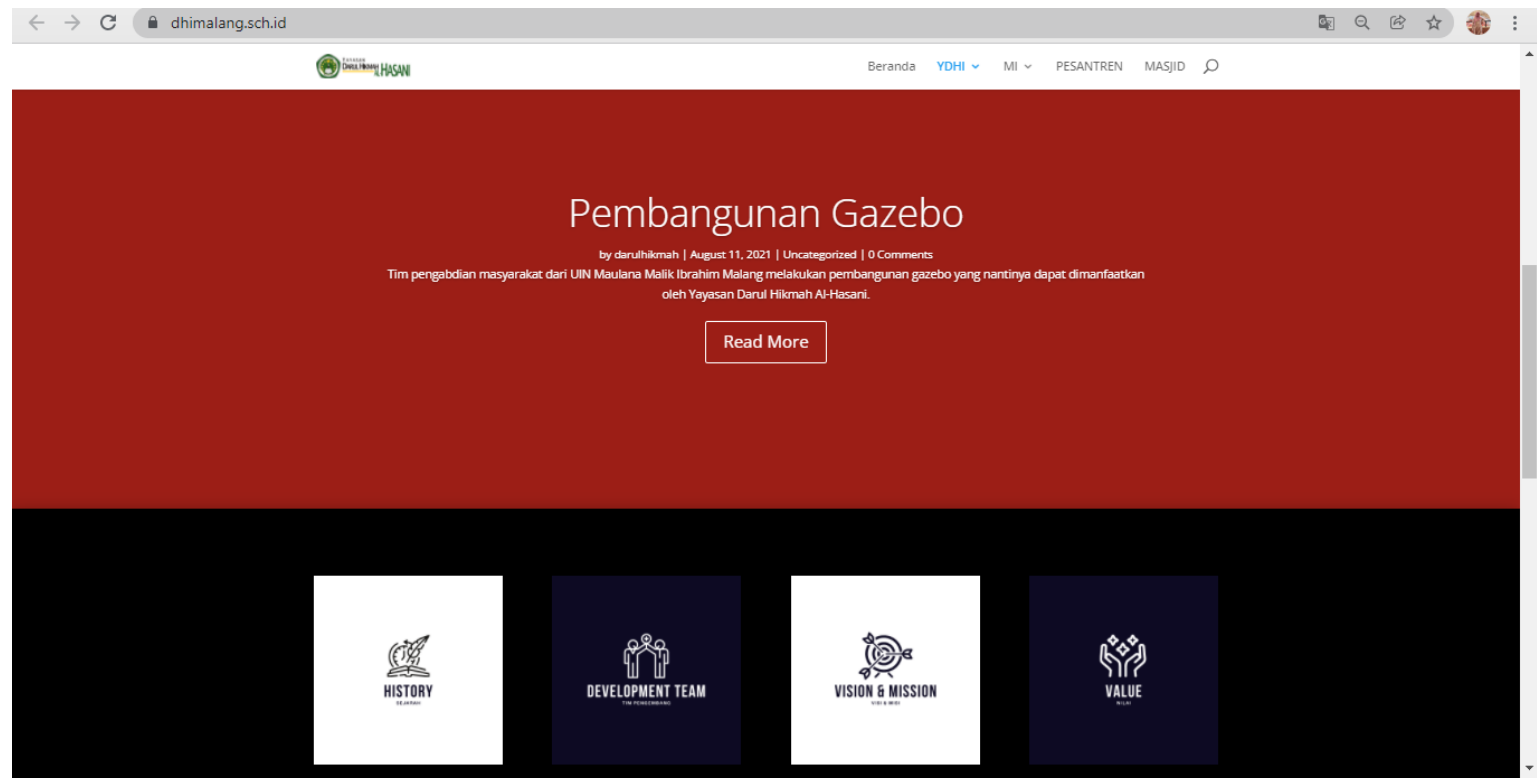

Gambar 4. Aktifitas Terkini dan Menu Pendukung Profil Yayasan

Tampilan selanjutnya berupa informasi terkini yang menggambarkan aktifitas dalam yayasan. Empat menu pertama untuk menjelaskan profil yayasan dibuat dalam bentuk gambar yang mengantarkan kepada link sejarah 
yayasan, tim pengembang yayasan, visi dan misi yayasan, serta nilai-nilai yang dikembangkan dalam yayasan. Semua nama menu bergambar dibuat dalam dua bahasa, yaitu bahasa Inggris dan Indonesia.

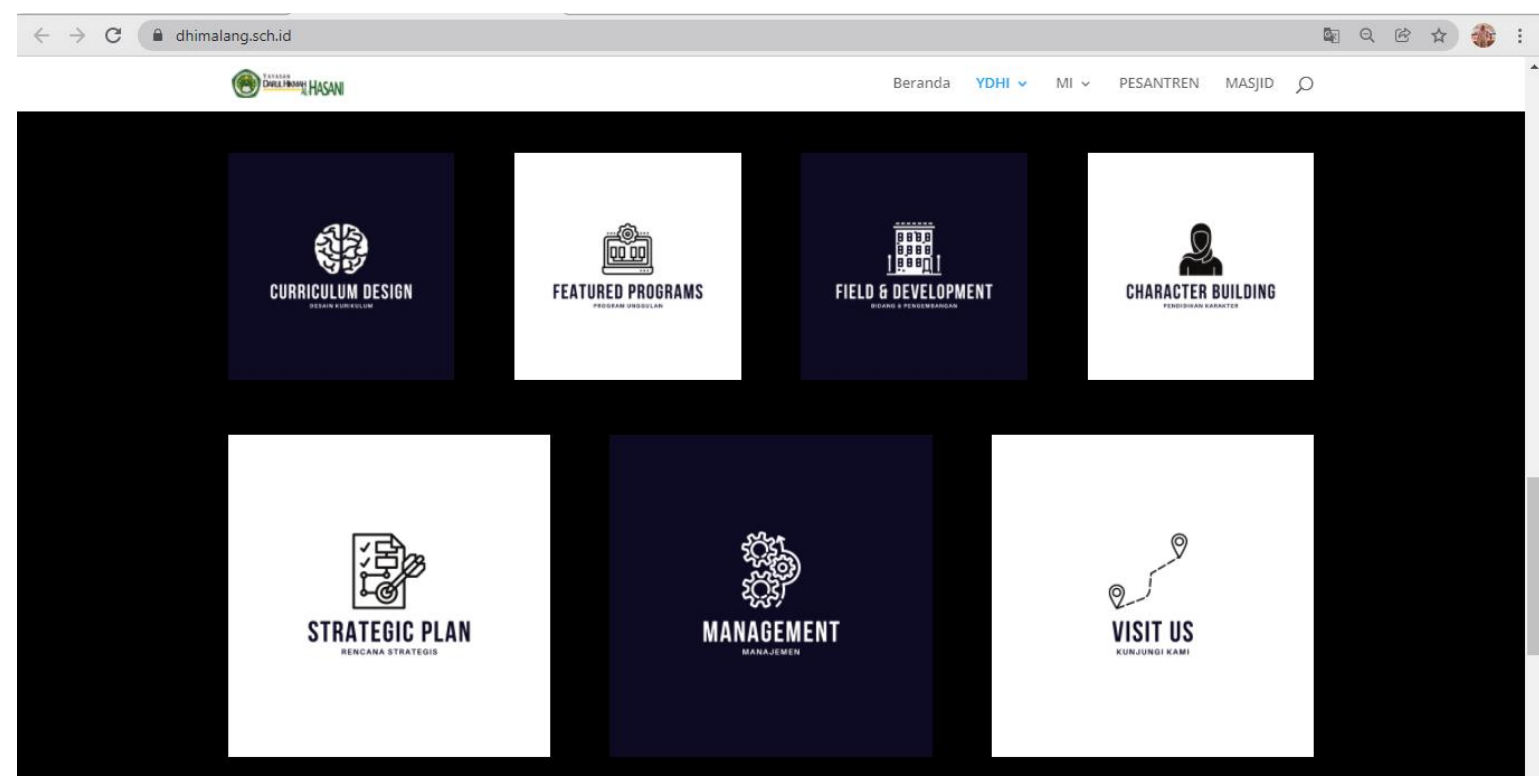

Gambar 5. Menu Lainnya

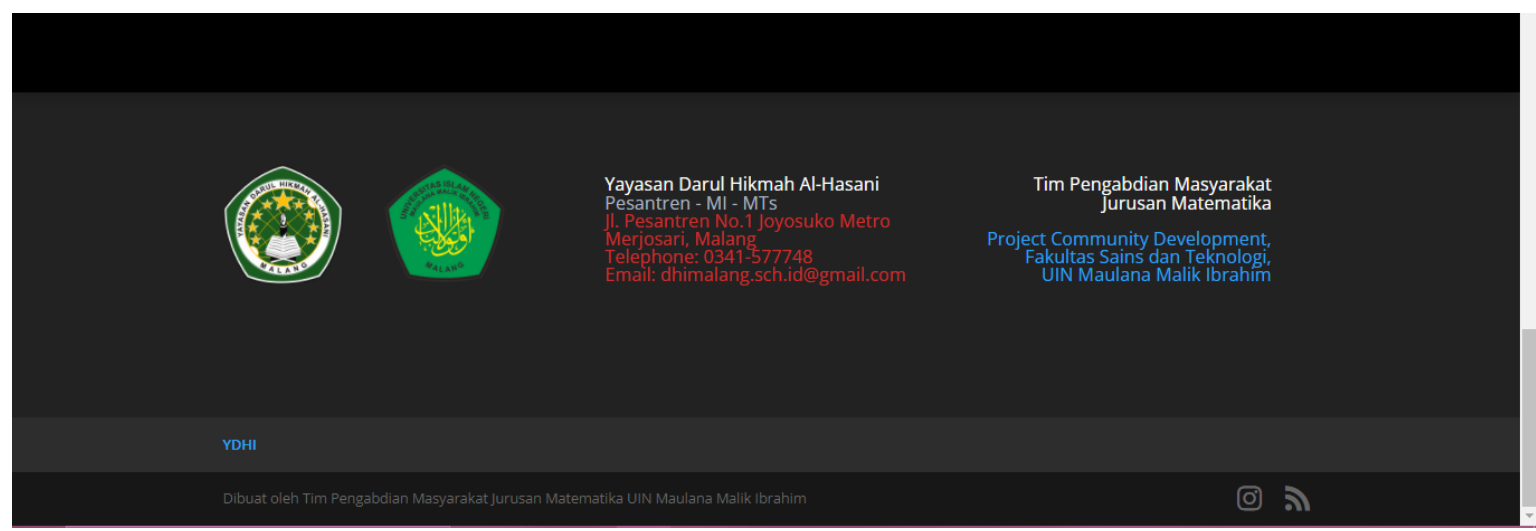

Gambar 6 Alamat Yayasan dan Tim Kerjasama

Sebagai bentuk kerja sama, maka di bagian akhir ditampilkan alamat yayasan dan tim pengabdian masyarakat. Keseluruhan proses terbentuknya alamat website beserta pengumpulan dan pengaturan isinya secara garis besar terangkum dalam tabel jadwal kegiatan berikut.

\begin{tabular}{|c|l|l|c|}
\hline No. & Jadwal Kegiatan & \multicolumn{1}{|c|}{ Kegiatan } & PIC \\
\hline 1 & 6-7 Mei 2021 & Survei Awal & Kelompok \\
\hline 2 & 10 Juni 2021 & Pendaftaran Hosting dan Domain & Kelompok \\
\hline 3 & 14-18 Juni 2021 & Pembuatan Website & Kelompok \\
\hline 4 & 21 Juni 2021 & Validasi Isi Webite & Kelompok \\
\hline 5 & 22-25 Juni 2021 & Revisi & Kelompok \\
\hline 6 & 28 Juni 2021 & Uji coba Website & Kelompok \\
\hline 7 & 5-9 Juli 2021 & Revisi Akhir & Kelompok \\
\hline 8 & 12 Juli 2021 & Publikasi dan Serah terima Website & Kelompok \\
\hline 9 & 12 Agustus 2021 & Evaluasi & Kelompok \\
\hline
\end{tabular}

Tabel 1. Tabel Jadwal Kegiatan 


\section{KESIMPULAN}

Berikut adalah beberapa kesimpulan dari hasil kegiatan pengabdian masyarakat yang sudah dilakukan

1) Website yayasan sebagai output dari kegiatan pengabdian kepada masyarakat digunakan sebagai sarana untuk memulai aktifitas publikasinya (termasuk info pendaftaran dan lain sebagainya).

2) Dampak dari kegiatan pengabdian masyarakat ini dinilai cukup besar karena website merupakan salah satu hal utama yang harus dimiliki oleh sekolah saat ini.

3) Kegiatan pengabdian masyarakat ini diharapkan dapat menjadi salah satu bentuk kerja sama Prodi Matematika UIN Malang pada khususnya dengan tempat-tempat binaan UIN Malang.

\section{UCAPAN TERIMAKASIH}

Tim Community Development Program tahun 2021 Program Studi Matematika mengucapkan terima kasih kepada Fakultas Sains dan Teknologi UIN Maulana Malik Ibrahim Malang yang telah mendukung kegiatan pengabdian, juga kepada Kepala Sekolah MI Darul Hikmah Al Hasani

\section{DAFTAR PUSTAKA}

[1] N. Brugger, "Website history and the website as an object of study," New Media Soc., vol. 11, no. 12, pp. 115-132, Feb. 2009, doi: 10.1177/1461444808099574.

[2] F. Al-Hawari, M. Al-Zu'bi, H. Barham, and W. Sararhah, "The GJU website development process and best practices," J. Cases Inf. Technol., vol. 23, no. 1, 2021, doi: 10.4018/JCIT.2021010102.

[3] H. Fahmi, W. P. Sari, and A. Kusumastuti, "Pengembangan Aplikasi Repositori Publikasi Penelitian dan Pengabdian Menggunakan Framework PHP Berbasis MVC," Publ. Libr. Inf. Sci., vol. 4, no. 1, pp. 8-12, Aug. 2020, doi: 10.24269/pls.v4i1.2396.

[4] J. Manhas, "Initial framework for website design and development," Int. J. Inf. Technol., vol. 9, no. 4, pp. 363-375, Dec. 2017, doi: 10.1007/s41870-017-0045-4.

[5] J. Almeida, M. Dabu, A. Manikutty, and P. Cao, "Profiding differentiated levels of service in web content hosting," 1998.

[6] P. V. Mockapetris and K. J. Dunlap, "Development of the Domain Name System," in Symposium Proceedings on Communications Architectures and Protocols, SIGCOMM 1988, Aug. 1988, pp. $123-$ 133, doi: $10.1145 / 52324.52338$. 